\title{
Nursing shortage, a different challenge in Iran: A systematic review
}

\author{
Aziz Shamsi*1(D), Hamid Peyravi
}

Received: 9 Feb 2019

Published: 19 Feb 2020

\section{Abstract}

Background: Nursing shortage is an important and multifaceted challenge in the health systems and has reached a warning threshold. The factors associated with nursing shortage vary from country to country. Therefore, this study compared the causes of nursing shortage and suggested strategies to help resolve this concern both in Iran and in the world.

Methods: To conduct this systematic review, search was done in English and Persian databases from 2000 to 2016 . In the preliminary review, 537 articles were included in the study. After reviewing the titles, abstracts, objectives, and results of articles, 32 studies were finalized.

Results: The important causes of nursing shortage in the world included aging of the nursing workforce, inadequate admission and training of nurses, aging population, and job abandonment. However, the leading causes in Iran were unwillingness and lack of desire to enter and remain in the nursing field, job abandonment, inadequate salaries, low social status, and negative perception of nursing. Proposed strategies in the world are increasing the salaries, redesigning the work environment, improving the public's perspective, retaining the existing nursing workforce, and flexible work schedules. In Iran, these strategies include increasing salaries and recruitment, enhancing the public's perception of nursing, and supporting nursing organizations.

Conclusion: Nursing shortage is a multifaceted concept with varying magnitudes in different countries. Therefore, the strategies to resolve nursing shortage should be based on the unique conditions of each country. The most important strategies to overcome nursing shortage in Iran are focused on the improving the retention of existing nursing workforce.

Keywords: Medically underserved area, Shortage, Iran, Nursing

\author{
Conflicts of Interest: None declared \\ Funding: None \\ *This work has been published under CC BY-NC-SA 1.0 license. \\ Copyright $\odot$ Iran University of Medical Sciences
}

Cite this article as: Shamsi A, Peyravi H. Nursing shortage, a different challenge in Iran: A systematic review. Med J Islam Repub Iran. 2020 (19 Feb);34:8. https://doi.org/10.47176/mjiri.34.8

\section{Introduction}

The importance of human health resources and their key role in maintaining and improving the health of the community is agreed upon by health care providers (1). The

Corresponding author: Aziz Shamsi, shamsi.a@tak.iums.ac.ir

1. Department of Medical-Surgical Nursing, School of Nursing and Midwifery, Iran University of Medical Sciences, Tehran, Iran

2. Department of Critical Care Nursing, Iran University of Medical Sciences, Tehran, Iran main problems of the hospitals, as the main provider of health care services, are rooted in the lack of manpower or its inappropriate distribution (2). Meanwhile, a nursing

\section{$\uparrow$ What is "already known" in this topic:}

Previous studies on nursing shortage have suggested some of the causes of nursing shortage and presented some strategies to address this problem.

\section{$\rightarrow$ What this article adds:}

In this study, the causes and strategies for addressing nursing shortage in the world and Iran were prioritized according to their importance. Having compared the causes of nursing shortage and the corresponding strategies, it became clear that increased age of nursing staff was the main cause of nursing shortage in the world, but unwillingness to enter and remain in the nursing profession was the main cause of nursing shortage in Iran. Nevertheless, the main strategy to overcome nursing shortage in Iran and the world is to increase nurses' salaries and rights. 
team is a vital part of the health care system, and comprises about $56 \%$ of any hospital's staff (3). Thus, its shortage can reduce the quality of health care services (4).

Assuring the quality of patient care is the basis of nursing practice (5). Therefore, any defect in persistent provision of nurses to respond to care needs is a serious threat that can threaten the quality of care (6). Quality nursing care can decrease hospital infection, length of hospital stay, mortality rate, cardiac arrest incidence, and other complications (7). Various studies have pointed to a shortage of nurses as an obstacle against the efficiency and quality of care (8-10).

Nursing shortage is a major challenge to health care systems and has reached a warning threshold (11). This shortage becomes evident when there are not enough nurses to provide a certain level of care or to fill vacant positions and budget allocations (12). Nursing shortage is an international problem in progress. According to the World Health Statistics 2013, it is estimated that 1 million additional nurses will be needed by 2020 (13). Also, health workforce shortage is estimated to be 7 million, and is expected to reach 12.9 million by 2035 (14).

Nursing shortage is a complex phenomenon associated with many factors (15). One study identified several factors for nursing shortage: low salaries; bad working conditions; poor management; weakness of the authorities in employing work force prioritizing women for nursing profession; and preferring African, Spanish, and Latin nurses (16). Nursing shortage is the consequence of reduced university student admissions, elderly workforce, competition for employing skilled workforce (17), increased demand due to aging population and customer needs, rapid technological development (18), globalization of the labor market, and increased inclination of nurses for alternative jobs (19).

Nursing shortage problem is a multifaceted problem (20) and its associated factors vary from one country to another (21). The main causes of nursing shortage in the world are insufficient university student admissions, lack of faculty members, aging of nurses and their early retirement, aging of the society, and the need for more care, inadequate employment, increase of stress, low job satisfaction, and willingness to leave the job (22). However, in Iran, the main factors associated with nursing shortage include low social status, work-related injuries, early retirement, immigration, and willingness to abandon the current job, employment in other professions, housekeeping, low employment rates, and the increase of hospital beds (1). Due to the economic dependence of the health and medical centers on the government in Iran, these canters need to obtain the necessary credentials for employment of nurses, which can pose a restriction against nurse recruitment or university student admission (23). In Iran, currently the shortage of nurses is about 130000 . There are about 1.3 nurses per 1000 population, and it is anticipated that in 2020, there will be a shortage of 200000 nurses (24). There is still a shortage of nurses in the United States although they have about 10 nurses per 1000 (20). Therefore, the concept of nursing shortage depends on the scope of practice for nurses, the geographic area of activity, and the balance of supply and demand in that community (24). In Iran, the problem of nursing shortage is recognized as the most important challenge in the field of nursing and it is in contrast with its global concept, requiring unique strategies (21).

Different studies have examined different aspects of nursing shortage and there is no comprehensive view on this issue. In addition, due to the differences in the concept of nursing shortage with respect to the context and considering the differences in the proposed strategies, this study aimed to identify and compare the causes of nursing shortage and the strategies used to solve this problem in Iran and in the world using a systematic review of the related studies.

\section{Methods}

In this systematic review, PubMed, Google Scholar, Science Direct, Ovid, and Scopus were explored to obtain related articles in English and SID, ISC, Magiran, Iranmedex, Medlib, and Google Scholar were reviewed to find related articles in Persian. The search strategy and the method of selecting articles were agreed upon by the researchers. For data extraction, a form was developed by the researchers which included the name of the authors, publication year, causes of nursing shortage, and the suggested strategies. According to Medical Subject Headings (MeSH), the keywords of "medically underserved area", "shortage", and "nurse" were used individually and in combination to search. Only papers published from early 2000 to the end of 2016 were included in the study. To avoid bias, the search was performed by 2 researchers independently and by using a data collection form. Agreement was reached about controversial cases through scientific discussion. The inclusion criteria were having research standards based on PRISMA checklist, being relevant, and having structure. The exclusion criterion was the lack of access to the full-text or the required data. The studies were reviewed and selected in 3 stages. First, the title was reviewed, and unrelated articles were excluded. In the second stage, having read the abstract, the related articles were selected. In the third stage, all included articles were quickly reviewed and duplicate studies removed (24 articles). In case of lack of access to full-texts, an email was sent to the corresponding author requesting the full-text of the article. Studies with insufficient data or without text ( 5 papers) were excluded from the study. Then, the texts and documents collected by each researcher were carefully examined during a discussion. According to the defined inclusion and exclusion criteria, 32 articles were selected and analyzed, which included descriptive studies, systematic reviews, and qualitative studies. The search stages are shown in Figure 1.

In the initial search, 537 articles were found. Having reviewed the titles, 263 articles were selected. After studying the abstracts, 148 out of 263 articles were included. By assessing the full-texts, objectives, and findings of the selected articles, 25 related papers in the world and 7 related papers in Iran were finally selected for analysis. The results on the causes of nursing shortage in the world and Iran are presented in Table 1. 


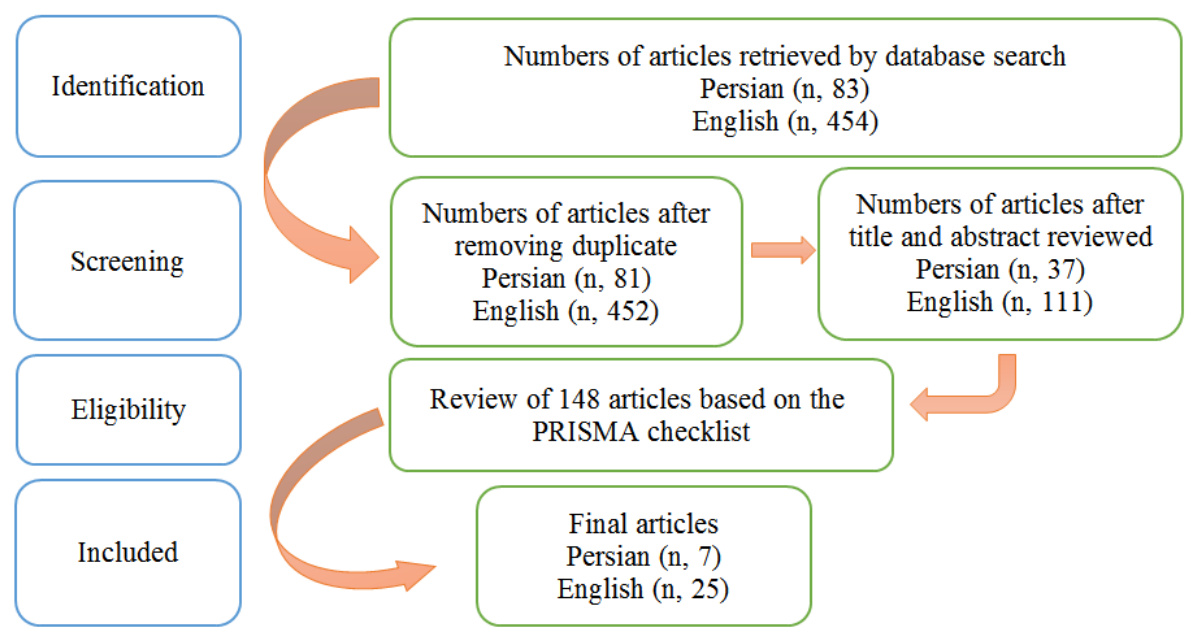

Fig. 1. Flow diagram showing the different phases involved in searching for relevant publication

Table 1. The results extracted from studies on nursing shortage in the world and in Iran

\begin{tabular}{|c|c|c|c|}
\hline Authors & Country & Causes & Strategies \\
\hline $\begin{array}{l}\text { Aboshaiqah, } 2016 \\
\text { (25) }\end{array}$ & KSA & $\begin{array}{l}\text { Unsuitability for women, public's negative view, } \\
\text { challenging work environment, and foreign labor } \\
\text { force }\end{array}$ & $\begin{array}{l}\text { Educating and awarding degrees to attract and improve } \\
\text { people's perspective toward nursing, using media to } \\
\text { achieve public's familiarization, and improving work- } \\
\text { ing conditions }\end{array}$ \\
\hline
\end{tabular}
al, 2016 (26)

Snavely, 2016 (27)

Abbaszadeh et al, $2015(24)$

Iran education and employment, performing no nursing tasks, social changes, and economic growth Job abandonment and employment in other pro-
fessions, aging and retirement, shortage of faculty members, and aging population

Aging population, inappropriate student recruitment policies, immigration, lack of faculty members, insufficient salaries, low social status, unwillingness to work, negative perception of nursing as a woman's occupation, and lack of understanding of the role of a nurse

$\begin{array}{ll}\begin{array}{l}\text { Atashzadeh et al, } \\ 2014(28)\end{array} & \text { Iran } \\ \begin{array}{l}\text { Rangriz et al, } 2015 \\ (1)\end{array} & \text { Iran } \\ \begin{array}{l}\text { Soudagar et al, } \\ 2014(29)\end{array} & \text { Iran }\end{array}$

2014 (29)

Iran

Ebadi et al, $2014 \quad$ Iran

ran

Dissatisfaction with profession, poor management, and improper social status.

Low employment rates, job change due to job burnout

Unwillingness to work because of being male, aging, stressful wards, contractual employment, and lack of interest

Increase of nursing education, and changing health systems policymakers

Increase of employment rates

Increase recruitment and retention of existing workforce, deploy nurses in other positions such as schools, increase job satisfaction, improve public's perception of nursing, support Nursing Organization, familiarize society with the role of a nurse, optimize the work environment, increase nursing student admissions, and increase salaries

Reduce the recruitment process and increase employment rates

Transfer of nursing personnel among different wards and improve employment status of contract-based nurses

Increase salaries and create financial incentives

mmigration, recruitment in office jobs, job abandonment, job burnout, low salaries, opening of new centers, medical advances, increase in the number of elderly people, improper social status, and long working hours

Cox et al, 2014 (31)

Aging of nurses and patients, insufficient recruitment, new nursing students, inadequate training of nursing students, and insufficient salaries

MacLean et al, 2014 (32)
Job abandonment due to improper planning, poor financial incentives, inappropriate geographical
Improvement of health care infrastructure, use of computer technology, change of tasks, and use of interprofessional care groups
After extracting, assessing, and analyzing the findings of the included studies, the researchers assigned the causes of nursing shortage into 6 categories of organizational factors, sociocultural factors, demographic characteristics, work-related factors, education-related factors, and job abandonment and grouped strategies into 3 main 


\begin{tabular}{|c|c|c|c|}
\hline Authors & Country & Causes & Strategies \\
\hline $\begin{array}{l}\text { Barnett et al, } 2010 \\
\text { (19) }\end{array}$ & Australia & - & $\begin{array}{l}\text { Increase of nursing departments/faculties and } \\
\text { nursing student admissions, improvement of pub- } \\
\text { lic's perception of nursing, improvement of profes- } \\
\text { sional self-image, decrease of students' withdraw- } \\
\text { al, encouragement of nurses' return, increase of } \\
\text { nurses' entrance and prevention of migration, } \\
\text { changing workforce combination and reduction of } \\
\text { reliance on RN nurses, recognition of nurses' roles, } \\
\text { improvement of salaries and the work environ- } \\
\text { ment, provision of independence and professional } \\
\text { power, flexible work schedules, improvement of } \\
\text { the structure of clinical work, increase of retire- } \\
\text { ment age, reduction of occupational risks, and } \\
\text { insurance against risks and mistakes }\end{array}$ \\
\hline
\end{tabular}

Duvall et al, $2010 \quad$ USA Management problems, stress, physical needs, inade(33)

Flinkman et al, 2010 (34)

Yun et al, $2010(35)$

Zarea et al, 2009

Fox et al, 2009 (36)

Morgan et al, 2009

Buchan et al, 2008 (20)

AbuAlRub, 2007 quate training, lack of faculty members, and hospital environments

Finland

Job abandonment, professionalism and organizational commitment, job satisfaction, low salaries, low probability of progress, and contradiction between work and life

China Inequality in pay and employment conditions of physicians and nurses, and immigration

Decrease of employment, hospitalization only, centralized system and lack of independence, human resource planning, lack of position for graduated nurses, job change, immigration, low salaries, low social status, reluctance to enter nursing, consideration of nursing as a women's job, lack of job valuation, negative attitudes toward women's work at night, the inability of girls to enter nursing, job abandonment of girls after marriage, low job security, poor working conditions, high workload, conflicts with doctors, management problems, lack of support from the work environment, unspecified tasks, and equipment shortages

USA Demographic imbalance, transfer of education from hospital to university, lack of faculty members and reduced university student admission, a variety of job opportunities along with restricted conditions for nursing restricted entry requirement, job abandonment, stressful work environment, shifts, occupational problems and diseases, new technology, imbalance in biological rhythms and life plans, lack of support against mistakes, decrease of salaries, repayment of the student loan at work, and job abandonment

USA Reduction in the number of nurses, elimination of nursing position, inadequate education, insufficient assessment of patient's needs, and inadequate support

USA Inappropriate work schedules, limited resources and supply reduction, poor implementation policies, poor retention and return of nurses, inadequate support

Jordan Low salaries compared to high workload, decrease in women's choice of nursing, decrease of the number of faculty members, unattractive working conditions, low social status, and decrease in the number of departments/faculties
Strategies related to causes

Improvement of health care system to increase retention, creation of strong educational infrastructure, and enhancement of public's perception

Support of the Nursing Organization, increase of employment rates, improvement of the public's perception using media, increase of financial benefits, improvement of working conditions, and improvement of the quality of professional life

Redesigning technology and the work environment to provide care to many patients while there are few nurses, employment of new nurses, performance-based payment

Increasing professional autonomy, working in a patient-centered environment, paying attention to employees' successes, increasing education of patient and employee, and increasing managerial support and supervision

Doing research on the factors enhancing nurses' retention, improving public's perception through the media, increasing the number of nursing faculties and nursing student admissions, and allocating scholarships for nursing students categories of increase in supply and decrease in demand, retention improvement, and reduction in job abandonment). In Table 2, the causes of nursing shortage in the world and in Iran are highlighted in order of priority and importance. Furthermore, the most important suggested strategies in order of priority and importance are presented 
Table 1. Ctd

\begin{tabular}{lcl}
\hline Authors & Country & \multicolumn{1}{c}{ Causes } \\
\hline Langan et al, & USA & $\begin{array}{l}\text { High workload, new technologies, lack of job securi- } \\
\text { ty, insufficient support, family responsibilities, re- } \\
\text { tirement, unclear personal reasons, lack of physica } \\
\text { strength and ability, and lack of sufficient incentives }\end{array}$ \\
Oulton, 2006 & Canada & $\begin{array}{l}\text { Aging population, globalization and growth of private } \\
\text { sector, increased demand for care, high workload, } \\
\text { insufficient support, violence, stress and burnout, } \\
\text { wage differentials, lack of participation in decision } \\
\text { making, and changes in human resources approaches }\end{array}$ \\
& &
\end{tabular}

Gassert, $2006 \quad$ USA -
(41)

Lynn et al, USA

(n)

$\begin{array}{lcl}\begin{array}{l}\text { Lynn et al, } \\ 2005(42)\end{array} & \text { USA } & \begin{array}{l}\text { Job abandonment, financial status, organizational } \\ \text { commitment, and low job satisfaction }\end{array} \\ \begin{array}{l}\text { Hooshmand } \\ \text { et al, 2004 } \\ \text { (43) }\end{array} & \text { Iran } & \begin{array}{l}\text { Job abandonment, failure to meet individual needs, } \\ \text { low salaries, non-academic nursing position in the } \\ \text { community, and lack of attention and support from } \\ \text { authorities }\end{array}\end{array}$

Ulrich, 2003 USA -

(44) authorities

Strategies
Increase of salaries, improvement of working
conditions, creation of rest breaks, provision of health
insurance, and provision of attractive supportive facilities

Changing major health policies, improving improper internal distribution and preventing migration, and appropriate nursing leadership

Using alternative methods to compensate for the lack of faculty members and low number of student admissions such as using clinical faculties, simulated learning environments, and clinical information systems

Developing professional nursing leaderships, increasing support and communication with managers, creating training opportunities for nurses, eliminating compulsory overtime, increasing salaries, employing new nurses and increasing nurses to patient ratios, engaging nurses in problem solving, simple and effective documentation, flexible work schedules, establishing kindergarten, reducing offduty activities, and improvement of nurses' retention

$-$ 


\begin{tabular}{|c|c|c|c|}
\hline \multicolumn{4}{|l|}{ Table 1. Ctd } \\
\hline Authors & Country & Causes & Strategies \\
\hline Lee, $2002(48)$ & $\overline{\text { USA }}$ & $\begin{array}{l}\text { Aging nurses, decrease in supply, and increase in } \\
\text { demand }\end{array}$ & $\begin{array}{l}\text { Designing work environment using information technolo- } \\
\text { gy and ergonomics, patient-centered staffing, hospital } \\
\text { collaboration with faculties, and employing men and } \\
\text { minorities }\end{array}$ \\
\hline $\begin{array}{l}\text { Zimmermann, } \\
2000 \text { (49) }\end{array}$ & USA & $\begin{array}{l}\text { Aging nurses, decrease in admissions, increase in job } \\
\text { opportunities and choices, increase in need for nurs- } \\
\text { es, changes in demographic characteristics of the } \\
\text { community, the desire of older nurses for part-time } \\
\text { work, and changes in care delivery systems }\end{array}$ & $\begin{array}{l}\text { Improving the employment and retention of nurses, de- } \\
\text { ployment of unemployed and immigrant workforce, en- } \\
\text { hancing public's perception of nursing, overtime, chang- } \\
\text { ing the work environment, collaboration of nurses with } \\
\text { different grades, and taking into account a mandatory ratio } \\
\text { for employees }\end{array}$ \\
\hline
\end{tabular}

Table 2. The most important causes of nursing shortage in the world and in Iran in order of importance and priority

\begin{tabular}{|c|c|}
\hline Causes of nursing shortage in the world & Causes of nursing shortage in Iran \\
\hline Aging nurses and increase of retirement requests & Unwillingness to enter and stay in nursing \\
\hline Inadequate nursing admissions and education & Job abandonment and trying other jobs \\
\hline Aging population and increase of the need for care & Insufficient salaries compared to other professions \\
\hline Job abandonment and employment in other professions & Low social status \\
\hline Improper planning for recruiting nurses & The negative impression of nursing as a woman's career \\
\hline Shortage of faculty members and nursing faculties & Poor policies and programs for recruitment of workforce \\
\hline Low salaries and benefits & Immigration to other countries \\
\hline Lack of support by managers and other staff & Insufficient support in the workplace \\
\hline Suggested strategies in the world & Suggested strategies in Iran \\
\hline Improving benefits and rewards & Increasing salaries and benefits \\
\hline Redesigning and creating a healthy work environment & Increasing employment rates \\
\hline Improving public's perception of nursing & Improving public's perception of nursing \\
\hline Improving retention of existing nurse & Supporting Nursing Organizations and scientific associations \\
\hline Flexible work schedules & Improving the work environment \\
\hline Increasing the number of nursing faculties and students' admissions & Increasing nursing students' admissions \\
\hline
\end{tabular}

despite the entering of young nurses in the profession, the shortage of nurses is not over (50). The mean age of the registered nurses (RN) is about 46 years and a large number of them will be retired in the next 10 to 15 years $(51)$. Nevertheless, the mean age of nurses in Iran is 35-38 years and this factor cannot lead to shortage of nurses in Iran (23).

One of the main causes of nursing shortage in Iran is the unwillingness and lack of desire to enter and stay in nursing or willingness to leave the job. The rate of job abandonment, the unwillingness of nurses to stay in their job, and comparing nursing with other occupations are highly important (52), such that the rate of job abandonment among nurses is $20 \%$ in the United States and it is estimated to reach $36 \%$ by 2020 (53). The high rates of job abandonment and lack of interest may be due to the fact that nursing is considered as a worthless profession for women in most countries (54). Although there are no statistics on the causes of lack of interest and willingness to stay in nursing in Iran (28), it seems that its low salary and benefits and low social level are influential factors contributing to this issue. In a study aimed at examining the process of Iranian nurses' job abandonment, it was found that dissatisfaction with the profession, management weakness, and inappropriate social status of nursing were the main causes of job abandonment of nurses in Iran (28).

The second leading cause of nursing shortage in the world is the inadequate nursing education associated with financial issues and academic shortcomings. In the United States, in 2012, nearly 80000 applications to enroll for undergraduate or postgraduate degrees were dropped due to inadequate faculty members, clinical environments, and classroom space (55). In Iran, inadequate nursing education is not the main cause of nursing shortage and it is ranked as the sixth reason. The low rank of this reason in Iran may be due to an effort made by relevant organizations to increase student admissions. In this regard, Abbaszadeh and Abdi quoted from the head of Iranian Nursing Organization that "the student admission capacity has increased from 7000 to 10000 in 2011." (24)

The third leading cause of shortage of nurses in the world is an increase in the elderly population and the need for further care, resulting in increased demand and exacerbated nursing shortages. According to the UN report, from 2015 to 2030 , the population over the age of 60 is projected to increase from 901 million to 1.4 billion (56), and the need for care and nursing will be increased subsequently (26). This is not the cause of nursing shortage in Iran, because the average age in Iran is 28.3 years (56). However, due to the increase in the population of the elderly, this problem will worsen the shortage of nursing in the coming years.

Insufficient nursing salary compared to that of other professions is the third leading cause of shortage of nurses in Iran. High salaries and benefits are one of the ways to attract and retain workforce $(19,39)$. This is the seventh cause of a shortage of nurses in the world, reflecting the low level of Iranian nurses' salary. In this regard, experts believe that to make sustainable changes, reforms should be developed in politics, laws, and public's perspective (57). Therefore, one of the reforms in the field of policies 
and laws can be the implementation of a tariff plan for nursing services to increase the salaries of nurses.

Nurses' inadequate employment causes stress, low job satisfaction, and a desire to leave the profession (22). This factor is one of the important causes of the shortage of nurses in the world and in Iran, with almost the same significance. In Iran, most health centers are economically nongovernmental and government-dependent and have limitations for workforce recruitment (23). In addition, many studies highlighted the low employment rates due to financial constraints in the world and considered it as one of the major causes of nursing shortage $(20,22,26,31$, 32).

Insufficient managerial support is one of the major causes of nursing shortage in the world and in Iran, with almost the same importance. Many studies pointed to the effective role of managers in the retention of the nurses and the reduction of job abandonment $(20,33,36)$. One of the management's efforts to retain human resources is to create job satisfaction and prevent employees' dissatisfaction (58).

Other cause of nursing shortage in Iran is immigration nurses from Iran to improve their economic status and quality of life, although the exact statistics are not available (24). Developed countries compensate their nursing shortages by resorting to the recruitment of nurses from poor and developing countries (59).

Nursing shortage strategies have been categorized into 3 categories: (1) supply increase and demand decrease, (2) retention improvement, and (3) decrease of job abandonment. Moreover, the improvement of salaries and benefits has been the main proposed strategy to overcome nursing shortages in the world and in Iran. Since manpower is the main source of production and service delivery in organizations and the most important factor contributing to the survival and success of organizations (60), retention of existing staff can be achieved by offering financial incentives $(19,39)$.

Given that work-related factors are the most important causes of nursing shortage in the world, optimization and improvement of the work environment is the second proposed strategy $(19,22,32,33,36,61,62)$. A better work environment for nurses is associated with reduced job dissatisfaction and job abandonment, which can successfully resolve nursing shortages (63). Therefore, nursing shortage cannot be solved with increasing student admissions, but long-term nurse workforce growth and retention can be achieved by providing a safe and supportive work environment for the nurses (19). In Iran, improving the work environment should be among the priorities for the resolution of nursing shortage, although this is not a priority among the proposed strategies.

The second strategy to solve this problem in Iran is increase in recruitment. In Iran, due to the centralized management system, the recruitment process is subject to limitations (23). Due to such limitations, researchers consider the support of the Nursing Organization as one of the strategies to deal with nursing shortage problem, as the Nursing Organization tries to create better nursing work conditions by reaching out to the Islamic Consultative
Assembly and other responsible organizations (21). However, studies conducted in different countries around the world have indicated that one strategy to recruit greater number of workforce is by providing nursing admission and recruitment for men, minorities, and different cultural groups $(44,46)$.

The third proposed strategy in Iran and the world is improving the public's view of nursing. In Iran, the social perception is one of the main reasons for nurses' dissatisfaction (64). Therefore, through promoting the public's view of nursing and familiarizing the society with the important role of a nurse using public media, the retention of existing nurses and recruitment of new workforce can be achieved.

Another important strategy used worldwide is improving the existing nurses' retention. The average of registered job abandonment among the nurses was about $17.2 \%$ in 2014 (65). However, the retention of the existing nurses can be increased and nurses' job abandonment can be reduced by improving salaries and benefits, improving the work environment, developing independence and professional power, supporting the existing workforce by the management team, and creating a flexible work schedule (19). Most researchers agree that retention of existing nurses is a priority (66). In Iran, various studies have also contributed to improving the retention of the existing nurses by providing strategies such as increasing salaries and benefits, optimizing the work environment, using nurses in other positions, improving the quality of professional life, transferring nursing staff among different hospital wards, and improving the employment status of nursing workforce $(21,24,29,30)$. Increasing the number of nursing students' admissions and the nursing faculties has been highlighted as an important strategy both in Iran and in the world. Admission of nursing students has been doubled in Iran in the previous years (64). Another strategy proposed in different countries around the world is to increase the recruitment of foreign nurses. Many studies conducted in the US have highlighted the importance of this strategy; thus, the NHS has asked the government to consider nursing in the list of occupation shortages and allow foreign nurses to enter the country without visa due to nursing shortage (67). In Iran, a reverse strategy should be used and necessary measures should be taken to prevent the migration of nurses from the country and develop conditions for their retention. However, this strategy has not been suggested in studies conducted in Iran.

One of the proposed strategies in Iran which is not done in other countries is to gain the support of the Nursing Organization and scientific associations. The suggestion of this strategy may be due to important role of the Nursing Organization in nursing-related policies (21). Therefore, nurses' retention, job satisfaction, social status, and recruitment can be achieved by supporting the Nursing Organization and improving the working conditions, benefits, and salaries of nurses.

\section{Conclusion}

To improve the retention of the existing nursing workforce, it is necessary to increase the salaries and 
benefits in proportion to workload and other professions, improve the work environment, value nursing profession, gain managers' support, use nurses in diverse positions, develop flexible work schedules in accordance with personal life, and create employment opportunities for newly graduated nurses. The public's view of the nursing profession should be improved through familiarizing people from childhood with the vital role of nurses in the health system, improving the community's familiarity with the scientific position of the nurses in the hospital, and using the public media to show the important role of the nurses in hospitals. Nursing shortage can be overcome by increasing the admissions of nursing students at universities, taking into account the necessary requirements, and recruiting larger number of graduated nurses in accordance with needs of health care system.

\section{Conflict of Interests}

The authors declare that they have no competing interests.

\section{References}

1. Rangriz H, Mossavi SZ. General Health Policies and The effect of burnout by overworks on the shortage of nurses in Iranian hospitals (A system dynamics approach). Stra Macro Poli Quart. 2015;2(7):4364.

2. Eastaugh SR. Hospital nurse productivity. J Health Care Finance. 2001;29(1):14-22.

3. Dall TM, Chen YJ, Seifert RF, Maddox PJ, Hogan PF. The economic value of professional nursing. Med care. 2009;47(1):97-104.

4. Sadeghifar J, Pourreza A, Ahmadi B, Zeraati H, Arab M. Assessment of necessary staff for hospitals of Ilam university of medical sciences in accordance with personnel criteria and standards of Iranian health ministry. Sci J Ilam Uni Med Sci. 2011;19(1):24-31.

5. Ross J. A looming public health crisis: the nursing shortage of today. J Perianesth Nurs. 2002;17(5):337-40.

6. Lynn MR, Redman RW. Staff nurses and their solutions to the nursing shortage. West J Nurs Res. 2006;28(6):678-93.

7. Talbert JJ. Distance education: one solution to the nursing shortage? Clin J Oncol Nurs. 2009;13(3):269.

8. Aiken LH, Sloane DM, Bruyneel L, Van den Heede K, Griffiths P, Busse R, et al. Nurse staffing and education and hospital mortality in nine European countries: a retrospective observational study. Lancet. 2014;383(9931):1824-30.

9. Duffin C. Increase in nurse numbers linked to better patient survival rates in ICU. Nur Stand. 2014;28(33)

10. Spetz J, Harless DW, Herrera C-N, Mark BA. Using minimum nurse staffing regulations to measure the relationship between nursing and hospital quality of care. Med Care Res Rev. 2013;70(4):380-99.

11. McMurtrie LJ, Cameron M, OLuanaigh P, Osborne YT. Keeping our nursing and midwifery workforce: Factors that support nonpractising clinicians to return to practice. Nurse Edu Today. 2014;34(5):761-5.

12. Goldfarb MG, Goldfarb RS, Long MC. Making sense of competing nursing shortage concepts. Policy Polit Nurs Pract. 2008;9(3):192202.

13. WHO. The world health statistics 2013. 2013. Retrived from https://www.who.int/gho/publications/world health_statistics/2013/e $\mathrm{n} /$.

14. WHO. Global Health Workforce Shortage to Reach 12.9 Million in Coming Decades. Retrived from http://www.who.int/mediacentre/ news/releases/2013/health-workforce-shortage/en/. 2013.

15. Walker AM. A perspective on the nursing shortage. Surg Neurol. 2009;71(1):81-2.

16. Slusher I, Withrow CN. Diversity: An Answer to the Nursing Shortage. Nurs Outlook. 2001;49(6).

17. Beyea SC. AORN's response to the nursing shortage in perioperative settings. AORN J. 2002;76(2):236-41.

18. Simoens S, Villeneuve M, Hurst J. OECD Health Working Papers, No. 19. Tackling Nurse Shortages in OECD Countries. OECD
Publishing (NJ1) Paris. 2005.

19. Barnett T, Namasivayam P, Narudin D. A critical review of the nursing shortage in Malaysia. Int Nurs Rev. 2010;57(1):32-9.

20. Buchan J, Aiken L. Solving nursing shortages: a common priority. J Clin Nurs. 2008;17(24):3262-8.

21. Zarea K, Negarandeh R, Dehghan-Nayeri N, Rezaei-Adaryani M. Nursing staff shortages and job satisfaction in Iran: Issues and challenges. Nurs Health Sci. 2009;11(3):326-31.

22. Rosseter R. Nursing shortage fact sheet. In: Nursing.(202) AAoCo, editor. 2014. p. 463-6930.

23. Farsi Z, Dehghan-Nayeri N, Negarandeh R, Broomand S. Nursing profession in Iran: an overview of opportunities and challenges. Japan J Nurs Sci. 2010;7(1):9-18.

24. Abbaszadeh A, Abdi A. Nursing shortage challenge: A Serious threat for the Health System: A Review Study. Comm Health J. 2015;9(1):37-47.

25. Aboshaiqah A. Strategies to address the nursing shortage in Saudi Arabia. Int Nurs Rev. 2016;63(3):499-506.

26. Abhicharttibutra K, Kunaviktikul W, Turale S, Wichaikhum OA, Srisuphan W. Analysis of a government policy to address nursing shortage and nursing education quality. Int Nurs Rev. 2016;0(0):0.

27. Snavely TM. A Brief Economic Analysis of the Looming Nursing Shortage In the United States. Nurs Econ. 2016;34(2):98.

28. Atashzadeh Shoorideh F, Rasouli M, Zagheri Tafreshi M. Nurses' Turnover Process: A Qualitative Research. J Qual Res Health Sci. 2014;3(1):62-79.

29. Soudagar S, Rambod M, Beheshtipoor N. Intention to Stay at Nursing Profession and Its Related Factors. Sadra Med Sci J. 2014;2(2 Apr)

30. Ebadi A, Khalili R. Nursing staff shortage in Iran: a serious challenge. J Hayat. 2014;20(1):1-5.

31. Cox P, Willis WK, Coustasse A. The American Epidemic: The US Nursing Shortage and Turnover Problem. Insights Chang World. 2014;2014(2).

32. MacLean L, Hassmiller S, Shaffer F, Rohrbaugh K, Collier T, Fairman J. Scale, causes, and implications of the primary care nursing shortage. Annu Rev Public Health. 2014;35:443-57.

33. Duvall JJ, Andrews DR. Using a structured review of the literature to identify key factors associated with the current nursing shortage. J Prof Nurs. 2010;26(5):309-17.

34. Flinkman M, Leino-Kilpi H, Salanterä S. Nurses' intention to leave the profession: integrative review. J Adv Nurs. 2010;66(7):1422-34

35. Yun H, Jie S, Anli J. Nursing shortage in China: State, causes, and strategy. Nurs outlook. 2010;58(3):122-8

36. Fox RL, Abrahamson K, editors. A critical examination of the US nursing shortage: Contributing factors, public policy implications. Nursing Forum; 2009: Wiley Online Library.

37. Morgan JC, Lynn MR. Satisfaction in nursing in the context of shortage. J Nurs Manag. 2009;17(3):401-10.

38. AbuAlRub RF. Nursing shortage in Jordan: what is the solution? J Prof Nurs. 2007;23(2):117-20.

39. Langan JC, Tadych RA, Kao CC. Exploring incentives for RNs to return to practice: A partial solution to the nursing shortage. J Prof Nurs. 2007;23(1):13-20.

40. Oulton JA. The global nursing shortage: an overview of issues and actions. Policy Polit Nurs Pract. 2006;7(3 suppl):34S-9S.

41. Gassert CA. Impact of technology and simulated learning on nursing shortages. Nurs Outlook. 2006;54(3):166-7.

42. Lynn MR, Redman RW. Faces of the nursing shortage: influences on staff nurses' intentions to leave their positions or nursing. J Nurs Adm. 2005;35(5):264-70.

43. Hooshmand Behabadi A, Sayf H, Nikbakht Nasrabadi A. Survey of nurse burnout in a 10 years period. Teb Va Tazkiyeh. 2004;13(4):010 .

44. Ulrich B. The nursing shortage and potential solutions: An overview. Nephrol Nurs J. 2003;30(4):364-76.

45. Janiszewski Goodin H. The nursing shortage in the United States of America: an integrative review of the literature. J Adv Nurs. 2003;43(4):335-43.

46. Murray MK. The nursing shortage: past, present, and future. J Nurs Adm. 2002;32(2):79-84

47. Meadows G. The nursing shortage: Can information technology help? Nurs Econ. 2002;20(1):46.

48. Lee SA. The Nursing Shortage: Insights and Perceptions. Front Health Serv Manage. 2002;19(2):29. 
49. Zimmermann PG. The nursing shortage: What can we do? J Emerg Nurs. 2000;26(6):579-82.

50. Potempa K. A future nursing shortage? Health Aff. 2012;31(3):652-

51. AACN AAoCoN. Sequestration: Estimating the impact on America's nursing workforce and healthcare discoveries. Retrieved from http://www.aacn.nche.edu/government-affairs/ AACNSequestra tion-Factsheet.pdf.2013.

52. Lee H, KIM MS, YOON JA. Role of internal marketing, organizational commitment, and job stress in discerning the turnover intention of Korean nurses. Japan J Nurs Sci. 2011;8(1):87-94.

53. De Gieter S, Hofmans J, Pepermans R. Revisiting the impact of job satisfaction and organizational commitment on nurse turnover intention: An individual differences analysis. Int $\mathrm{J}$ Nurs Stud. 2011;48(12):1562-9.

54. Buchan J. Global nursing shortages. BMJ. 2002;324(7340):751-2.

55. AACN AAoCoN. Nursing faculty shortage fact sheet. Retrieved from http://www.aacn.nche.edu/media-relations/NrsgShortageFS.pdf. 2015.

56. UN UN. Population Division World Population Ageing 2015. Department of Economic and Social Affairs, (ST/ESA/SER.A/390). 2015.

57. Nevidjon B, Erickson JI. The nursing shortage: solutions for the short and long term. Online J Issues Nurs. 2000;6(1):4-

58. Rahimi A, Ahmadi F, Akhond M. An investigation of amount and factors affecting nurses' job stress in some hospitals in Tehran. Hayat. 2004;10(3):13-22

59. Ross SJ, Polsky D, Sochalski J. Nursing shortages and international nurse migration. Int Nurs Rev. 2005;52(4):253-62.

60. Dean BB, Crawley JA, Schmitt CM, Ofman JJ. The association between worker productivity and quality of life in GERD. Am J Gastroenterol. 2001;96(9):S276-S7.

61. Bradley C. Messages from the field: Nurses' views on the shortage, the workplace, and their careers. Nurse Lead. 2003;1(4):26-9.

62. Wright PD, Bretthauer KM. Strategies for addressing the nursing shortage: Coordinated decision making and workforce flexibility. Decision Sci. 2010;41(2):373-401.

63. Liu K, You LM, Chen SX, Hao YT, Zhu XW, Zhang LF, et al. The relationship between hospital work environment and nurse outcomes in Guangdong, China: a nurse questionnaire survey. J Clin Nurs. 2012;21(9-10):1476-85.

64. Mirzabiegi M. Important approach of the Ministry of Health to offset the shortage of nurses. Treatment Industry Monthly. 2015.

65. Nursing Solutions I. 2016 National Healthcare Retention \& RN Staffing Report. Retrived from http://www.nsinursingsolutions.com/ administrators/admin-research/retentioninstitute.aspx. 2016.

66. Armstrong F. Confronting the nursing shortage. Aust Nurs J. 2002;10(6):22.

67. Smith J. Nursing put on shortage occupancy list for visas. Nurs Stand. 2015;30(8):8. 